\title{
UPPER GI ENDOSCOPY
}

\section{A REVIEW OF 100 CASES AT INDEPENDENT MEDICAL COLLEGE / INDEPENDENT UNIVERSITY HOSPITAL, FAISALABAD}

\author{
Dr. Muhammad Zakria', Dr. Awais Shuja², Dr. Abid Rashid ${ }^{3}$
}

1. MBBS, FCPS (Med) Assistant Professor, IMC / IUH,Faisalabad.

2. MBBS, FRCS, FCPS (Surg)

Assistant Professor,

IMC / IUH, Faisalabad.

3. MBBS, FCPS

Professor

IMC / IUH, Faisalabad.

Correspondence Address:

Dr. Muhammad Zakria

Assistant Professer,

IMC / IUH, Faisalabad.

zakriadr@yahoo.com

Article received on:

19/04/2014

Accepted for Publication:

$15 / 05 / 2014$

Received after proof reading:

$27 / 05 / 2014$

\begin{abstract}
Objective: To document various endoscopic findings in patients undergoing upper Gl endoscopy in our endoscopy unit. Design: Observational. Patients and methods: The data of 100 patients who underwent upper Gl endoscopy in Endoscopy Unit of Independent Medical College/ Independent University Hospital from April 2010 to December 2012 was analyzed. Demographic features, reasons for referral and endoscopic diagnoses were noted. Results: Among 100 patients, 35\% were referred due to persistent vomiting, $28 \%$ due to epigastric pain / discomfort, $18 \%$ due to dyspepsia and $7 \%$ due to retrosternal burning and upper gastrointestinal bleeding. Common endoscopic diagnoses were gastritis (28\%), duodenitis (14\%), gastroesophageal reflux disease / esophagitis $(6 \%)$, esophageal varices $(5 \%)$ and esophageal growth (4\%). Conclusions: The most common presenting complaint was persistent vomiting followed by epigastric pain / discomfort and the most common endoscopic finding was gastritis.
\end{abstract}

Key words: $\quad$ Upper Gl endoscopy, gastritis

Article Citation: Zakria M, Shuja A, Rashid A. Upper gi endoscopy - a review of 100 cases at independent medical college / independent university hospital, Faisalabad. Professional Med J 2014;21(3): 460-464.

\section{INTRODUCTION}

Upper Gastrointestinal (UGI) complaints are very common, both in indoor and outdoor practice. Sometimes, they create great diagnostic difficulty. Chronic and recurrent dyspeptic symptoms such as epigastric pain, postprandial fullness, and early satiety are common in the general population ${ }^{1,2}$. The performance of flexible endoscopy has brought significant changes in gastroenterology. Endoscopic examinations sensitivity and specificity are much higher in comparison to $x$-ray examination of the digestive tract, particularly in smaller lesions ${ }^{3}$.

Diagnostic and therapeutic upper Gl endoscopy which is now performed as the first initial examination instead of barium meal is of high value in evaluation and to explore these symptoms ${ }^{4,5,6}$. So, in many centers, UGI endoscopy has become the initial and usually sole diagnostic approach to unexplained UGI symptoms.
Independent Medical College/ Independent University Hospital has recently been established. It has a very large referral area in local vicinity i.e, Marzipura from Faisalabad main city, and adjoining areas of Chiniot, Narwala Bangla and different chaks from Narwala Bypass. The objective of the study was to find out common reasons of referral for UGI endoscopy in the endoscopy unit of this institution, demographic features of referred patients and common endoscopic diagnoses.

\section{PATIENTS AND METHODS}

Study design An observational study was conducted that included the data of first 100 patients who underwent UGI endoscopy in our endoscopy unit from April 2010 to December 2012. Patients were referred from inpatient, outpatient and accident \& emergency departments. 


\section{Inclusion criteria}

Patients aged $=14$ years of either sexes are included in this study.

\section{Exclusion criteria}

Patients with conditions that could result in emergency endoscopies (e.g., gastro-enterologic hemorrhage and ingestion of caustic substances or foreign bodies).

\section{Endoscopy}

A written informed consent was taken from every patient before the procedure. Olympus fiberoptic Video gastroscope was used. Banding was available (Saeed Six Shooter multiple band ligator). Patient preparation consisted of a 6-hour fast prior to endoscopy. IV line was maintained to cope with any situation during procedure, if patient bleed or went into vasovagal shock. A local pharyngeal anesthetic was administered (4\% xylocaine solution was used for gargles) prior to the procedure. Dormicom IV was given to anxious non-cirrhotic patients.

The patient was placed in the left lateral decubitus position and a mouth guard inserted. The endoscopist passed the extreme distal end of the endoscope through the mouth guard, observing through the eyepiece or monitor its passage over the tongue, then the epiglottis and vocal cords, the interior of the esophagus, continuing in this manner until reaching the second segment of the duodenum. On reaching this point, the endoscope was slowly retracted, the endoscopist examining the entire trajectory through which the instrument had advanced.

Parameters recorded were age and sex of the patients, indications for endoscopy, endoscopic diagnoses, and the types of therapeutic intervention.

The data was entered in SPSS 10 software. The quantitative data was recorded as mean and standard deviation and qualitative data as percentage.

\section{RESULTS}

From 100 patients undergone upper GI endoscopy, 33(33\%) were male and $67(67 \%)$ were female. The mean age of the patients was $42.45 \pm 16.52$ years. The patients were mainly between 30 and 50 years of age (as shown in table I ). Sixty six patients were referred from inpatient Department ( including M.U.I , M.U.II , Surgical ward and Private ward ), Twenty three patients were referred from Outpatient and Eleven from Accident and Emergency departments.

\begin{tabular}{|c|c|c|c|}
\hline Age group (Yrs) & Women & Men & Total \\
\hline$<20$ & 5 & 1 & 6 \\
\hline $20-29$ & 11 & 7 & 18 \\
\hline $30-39$ & 15 & 10 & 25 \\
\hline $40-49$ & 14 & 6 & 20 \\
\hline $50-59$ & 13 & 3 & 16 \\
\hline $60-69$ & 6 & 4 & 10 \\
\hline $70-79$ & 2 & 2 & 4 \\
\hline$\geq 80$ & 1 & 0 & 1 \\
\hline Total & 67 & 33 & 100 \\
\hline \begin{tabular}{c} 
Table-I. Age group and Sex of 100 patients. \\
\hline Women 67\% of total; Men 33\%; Ratio F/M = 2/1
\end{tabular} \\
\hline
\end{tabular}

The common indications for endoscopy were persistent vomiting, epigastrium pain / discomfort, dyspepsia, retrosternal burning, heamatemesis and dysphagia also shown in Table II. Other indications were iron deficiency anemia , chronic diarrhea, weight loss, anorexia and atypical chest pain. Out of 100 patients, fourteen were HCV+ve, only two were $\mathrm{HBV}+\mathrm{ve}$ and eighty four were $\mathrm{HBV} / \mathrm{HCV}$-ve. Out of fourteen HCV+ve patients, seven patients presented with heamatemesis, of which five patients had esophageal varices and four with gastropathy (three-NSAID-induced and one Portal hypertensive gastropathy).

The common endoscopic findings were normal 33(33\%), Gastritis 28 (28\%), Duodenitis 14 (14\%), Gastroesophageal reflux disease / Esophagitis 06 (6\%), Esophageal varices 05 (5\%), Esophageal growth 04 (04\%), NSAID-induced gastropathy 03 
(3\%), Mallory-Weiss tear 02 (2\%), Pyloric stenosis $02(2 \%)$, gastric ulcer $02(2 \%)$ and esophageal stricture 01 (01\%) shown in Table III. Other findings also seen in these patients were portal hypertensive gastropathy, rudemantry pouch in esophagus, esophageal candidiasis and bleeding diathesis.

The endoscopic procedure was diagnostic in 97(97\%) patients and therapeutic intervention (endoscopic variceal band ligation) was carried out in $03(3 \%)$ patients.

\begin{tabular}{|l|c|c|}
\hline \multicolumn{1}{|c|}{ Indications } & No & \%age \\
\hline Persistent vomiting & 35 & 35.0 \\
\hline Epigastric pain / Discomfort & 28 & 28.0 \\
\hline Dyspepsia & 18 & 18.0 \\
\hline Retrosternal burning & 07 & 7.0 \\
\hline UGl Bleed & 07 & 7.0 \\
\hline Dysphagia & 05 & 5.0 \\
\hline
\end{tabular}

Table-II. Common indications for UGI endoscopy

\begin{tabular}{|l|c|c|}
\hline \multicolumn{1}{|c|}{ Diagnosis } & No & $\%$ age \\
\hline Normal & 33 & 33.0 \\
\hline Gastritis & 28 & 28.0 \\
\hline Duodeninitis & 14 & 14.0 \\
\hline Gastroesophageal reflux \\
disease / esophagitis & 06 & 6.0 \\
\hline Esophageal varices & 05 & 5.0 \\
\hline Esophageal growth & 04 & 4.0 \\
\hline NSAID-induced gastropathy & 03 & 3.0 \\
\hline Mallory-Weiss tear & 02 & 2.0 \\
\hline Pyloric stenosis & 02 & 2.0 \\
\hline Gastric ulcer & 02 & 2.0 \\
\hline Esophageal stricture & 01 & 1.0 \\
\hline Table-III. Common endoscopic diagnoses \\
\hline
\end{tabular}

\section{DISCUSSION}

Our hospital is a budding medical college / hospital providing medical facilities to vast areas of Marzipura, from Faisalabad main city, and adjoining areas of Chiniot, Narwala Bangla and different chaks from Narwala Bypass. So our results reflect attitudes towards utilizing invasive diagnostic facilities, trends of referral, and prevalence of various diseases for which diagnostic and therapeutic UGI endoscopy is required, in this part of our city.

We provide endoscopic services to patients who are adults and older children as we do not have pediatric endoscopes. At present, we do not provide emergency endoscopic service during evening and night. Age and sex ratio of our patients was a reflection of outdoor consultation and indoor admission patterns regarding these parameters and was similar to those of studies from other parts of our country?.

Our study presents the data on diseases of the upper Gl tract for defi ned population in this area of the citry. Chronic and recurrent dyspeptic symptoms such as epigastric pain, postprandial fullness, and early satiety are common in the general population. In our study, most of the patient also present with vomiting, epigastric discomfort and dyspepsia.i.e very comparable with other studies ${ }^{1,2}$.

The relative frequencies of diagnosis of the principal diseases of the upper Gl tract obtained in primary care were the ones expected when compared with a series of consecutive endoscopies performed at IGE in 2007. The frequency of diagnosis in a series of 1575 patients seen consecutively in IGE showed that gastritis was also the most frequent (82\%), followed by hiatal hernia (31.6\%), duodenitis (31.1\%), duodenal ulcer (9.7\%), esophagitis (9.4\%), gastric ulcer $(3.4 \%)$ and malignant lesions $(0.95 \%)^{8}$. Our study also shows Gastritis at the top , followed by duodenitis, GERD/Esophagitis , esophageal growth and gastric ulcer. It is very coparable with the study, some variation may be due to geographical variation and eating habits with food 
quality at different areas of the world.

We found endoscopic gastritis in 28 out of 100 $(28 \%)$ cases. The most commonly seen endoscopic gastritis type according to Sydney System ${ }^{9}$ was endoscopic erythematous/exudative gastritis, which was indeed the most commonly observed endoscopic gastritis in adulthood ${ }^{9,10}$. The most commonly detected localization of gastritis was antrum which was also seen in our patients ${ }^{9}$. Another study by Aoki K, et al ${ }^{11}$ reported gastric prevalence which is most frequent in the population . Du J, Liu J. et al ${ }^{12}$ also reported that in Chinese population most frequent is gastritis followed by GERD/esophagitis . Same frequencies seen in our study.

An early endoscopy in cases of UGI bleeding has considerably altered the older concept of the causes of bleeding but the consequences of the events have remained the same. In our study, patient presented with Heamatenmesis were turned to be diagnosed as case of esophageal varices followed by Gastropath (included both NSAID-induced and Portal hypertensive gastropathy) and peptic ulcer. In a prospective series of 1000 cases of UGI bleeding, peptic ulcer was the most common cause $(55 \%)$ followed by esophageal varices $(14 \%)^{13}$. In an another data, peptic ulcer disease was responsible for only $21 \%$ of episodes of UGI bleeding and esophageal varices for $12 \%$ of episodes ${ }^{14}$. Non-specific mucosal abnormalities were the commonest cause of bleeding in this series. In our study, esophageal varices were the most common cause $(58 \%)$, followed by peptic ulcer disease $(11 \%)$, esophagitis and NSAIDs-induced gastric erosions.

Gastric ulcer is detected in our study, while duodenal ulcer was not seen. Although we have duodenitis in most patients .It could be due to frequent use of acid suppressing drugs by medical practitioners in patients with symptoms of dyspepsia. Alcohol consumption appeared to play little role as a cause of UGI bleeding in this population, most likely due to religious prohibition of alcohol in the society.Gastric ulcers were more common as compared to duodenal ulcers and this finding is similar to that seen in studies conducted in Western countries ${ }^{13,14}$, though a local case series gave an opposite result ${ }^{15}$.

The high incidence of esophageal varices was due to the high rate of chronic infection with Hepatitis $\mathrm{C}$ and $B$ leading to end stage liver disease. Our results shows the same and are comparable with studies conducted in Pakistan ${ }^{15-18}$. The frequency of normal endoscopy in patients presenting with UGI bleeding varies from 9 to $21 \%$ between different studies ${ }^{19}$ and it was 33\% in our study. Tumors of upper Gl tract are less common in our study, but similar data is shown by local studies ${ }^{16}$.

\section{CONCLUSIONS}

Upper Gl endoscopy is the only reliable tool for correctly determining the etiology of upper Gl complaints and it also has therapeutic potential. Persistent vomiting followed by epigastric pain / discomfort is the most common reason for referral to endoscopic unit and gastritis followed by duodenitis form the major bulk of endoscopic findings reflecting high prevalence of these diseases.

\section{Copyright@ 15 May, 2014.}

\section{REFERENCES}

1. Talley NJ, Vakil NB, Moayyedi P. American Gastroenterological Association technical review on the evaluation of dyspepsia. Gastroenterology 2005; $129: 1756-80$.

2. National Institute for Health and Clinical Excellence . Dyspepsia: managing dyspepsia in adults in primary care. 2004 .NICEguideline..

3. Endoscopic findings in the proximal part of the digestive tract in patients with chronic renal failure undergoing chronic dialysis program. Suzana Raicevic Sibinovic1, Aleksandar Nagorni1, Radomir Raicevic 2, Vesna Brzacki1, Miroslav Stojanovic3 ----- FACTA UNIVERSITATIS , Series: Medicine and Biology Vol.13, No 2, 2006, pp. 84 89.

4. Tedesco FJ, Endoscopy in the evaluation of patients - with upper gastro intestinal symptoms patients - with upper gastrointestinal symptoms indications, expectations and interpretations. J.Clin. Gastroenterol. 1981;3(suppl 2): 67-71. 
5. Health and public commeetti, American College of Physicians, Phelidelphia, Pennysylivania., Clinical compet in diagnostic OGD. Annals of internal Medicine1987; 937-939

6. The working party of the clinical sevices committee of the Britishsociety of gastroenterology. Provision of Gl endoscopy and relevant services for District general hospital , Gut 1991;32: 95-100.

7. Qureshi H, Banatwala NN, Sarwar J, Zuberi SJ. Emergency endoscopy in UGI bleeding. JPMA, Feb 1988; 30-8.

8. Sistema. ProGastro [Internet]. [place unknown]: Rincón Grupo Sapiem; 2008. Available from: http://gruposapiem.wordpress.com/windowsapp/si stema-progastro/. Spanish.

9. Tytgat GN. The Sydney System: endoscopic division. Endoscopic appearences in gastritis/duodenitis. J Gastroenterol Hepatol 1991; 6: $223-234$

10. Wyllie R, Mahajan L. Chronic abdominal pain of childhood and adolecence. In: Wyllie R, Hyams JS (eds). Pediatric gastrointestinal disease (2nd ed). London: W.B. Saunders Co; 1999:3-13.

11. Aoki K, Kihaile PE, Wenyuan Z, Xianghang Z, Castro $M$, Disla $M$, et al. Comparison of Prevalence of Chronic Atrophic Gastritis in Japan, China, Tanzania, and the Dominican Republic. Ann Epidemiol. 2005 Sep;15(8):598-606.

12. Du J, Liu J, Zhang H, Yu CH, Li YM. Risk factors for gastroesophageal refl ux disease, refl ux esophagitis and non-erosive refl ux disease among Chinese patients undergoing upper gastrointestinal endoscopic examination. World $\mathrm{J}$
Gastroenterol. 2007 Dec 7;13(45):6009-15.

13. Jutabha R, Jensen DM. Management of severe upper gastrointestinal bleeding in the patient with liver disease. Med Clin North Am 1996; $80: 1035$

14. Boonpongmanee S, Fleischer DE, Pezzullo JC, Collier K, Mayoral W, Al-Kawas F, et al. The frequency of peptic ulcer as a cause of upper-GI bleeding is exaggerated. Gastrointest Endosc 2004; 59:788-94.

15. Mahmood K, Saeedi MI, Muhammad R, Din Z. Upper gastrointestinal endoscopic findings in patients with dyspepsia. J Postgrad Med Ins 2006; 20 (1): 70-3.

16. Adam T, Javed F, Khan S. Upper gastrointestinal bleeding: An etiological study of 552 cases. J Pak Inst Med Sci 2004; 15 (1): 845-8.

17. Khurram M, Khaar HB, Hasan Z, Umar M, Javed S, Asghar $T$, et al. A 12 year audit of upper gastrointestinal endoscopic procedures. JCPSP 2003; $13(6)$ : 321-4.

18. Khurram M, Javed S, Khaar HB, Goraya F, Hasan Z. Endoscopic evaluation of 2484 patients with upper GI hemorrhage. J Rawal Med Coll 2003; 7 (2): 89-91.

19. Rockall TA, Logan RF, Devlin HB, Northfield TC: Incidence of and mortality from acute upper gastrointestinal haemorrhage in the United Kingdom. Steering Committee and members of the National Audit of Acute Upper Gastrointestinal Haemorrhage. Br Med J 1995; 311:222.

\section{6 min \\ strongest amongst you is he who subdues his self.}

